\title{
Estudo Comparativo entre a Presença de Placa Visível e Cárie Dentária em Crianças de 18 a 40 meses de 2 Populações Distintas
}

\author{
Comparative Study between the Presence of Visible \\ Plaque and Tooth Decay in Children from \\ 18 to 40 months of Age in Distinct Populations
}

Fernanda Gomes Milanez*

Luiz Reynaldo de Figueiredo Walter**

\begin{abstract}
MILANEZ F. G.; WALTER, L.R.F. Estudo Comparativo entre a Presença de Placa Visível e Cárie Dentária em Crianças de 18 a 40 Meses de 2 Populações Distintas. Semina, Londrina, v. 18, ed. especial, p.47-50, fev. 1997.
\end{abstract}

\begin{abstract}
RESUMO: O presente trabalho, avaliou a presença de placa visivel e de cárie dentária em 70 crianças de 18 a 40 meses de idade que freqüentavam duas creches distintas: uma com atendimento odontológico precoce e a outra sem esse atendimento. Na amostra estudada verificou-se que as crianças da creche que não possuia atendimento odontológico precoce apresentaram um maior percentual de placa visível. En relação à cárie dentária, esta mesma população apresentou maior número de crianças com presença de cárie, o que parece demonstrar que a placa visível é um indicativo de risco de cárie. Os resultados mostram a importância do atendimento precoce, principalmente através da educação dos pais quanto à higiene dental no sentido de promover a saúde bucal da criança.

PALAVRAS CHAVE: Risco de Cárie; Placa Visível; Cárie Dentária; Atendimento Precoce.
\end{abstract}

ABSTRACT: The present study has evaluated the presence of visible plaque and tooth decay in 70 children aged from 18 to 40 months who were attended by two distinct day-nurseries: one of them had early dental care and the other did not. In the sample studied, it was verified that those children who were attended by the day-nursery without early dental care presented a higher percentile of visible plaque. About tooth decay, this same population showed a higher number of children affected. This seems to demonstrate that the visible plaque is an indicator of caries risk. These results indicate the importance of early attention, specially through the parents education about dental care to promote the child oral health. KEY WORDS: Caries Risk; Visible Plaque; Tooth Decay; Early Attention.

Autori: Aluna do $5^{\circ}$ ano de Graduaçio em Odontologia da Universidade Estadual de Londrina.

Orientador: Livre-docente, Doutor em Odontopediatria/Professor Titular de Odontopediatria da Universidade Estadual de Londrina/Centro de Ciências da Saúde-

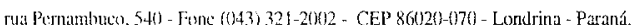




\section{INTRODUÇÃO}

Apesar da preocupação de alguns autores quanto aos cuidados odontológicos em bebês, só recentemente esses cuidados passaram a receber uma atenção maior por parte do cirurgião-dentista, que entendeu a necessidade de mudanças em seu comportamento na educação para a promoção da saúde, estabelecendo programas de educação, medidas preventivas e de controle da cárie, atenção primária e tratamento curativo específico para prevenir ou controlar as doenças mais freqüentes da cavidade bucal dos bebês.

Inicia-se, então, uma nova filosofia de atenção odontológica a nível mundial. $O$ tratamento curativo cede lugar ao conceito de atenção precoce, onde muito mais importante do que a cura da doença é a possibilidade de impedir que ela se instale, através da manutenção da saúde bucal.

Apesar da prevalência de cárie nos $1^{\circ}$ anos de vida ainda ser um assunto muito discutido, alguns autores chegaram a resultados relevantes que enfatizam a importância da Odontologia para bebês.

ALBERT et al. ', em 1988, relataram o diagnóstico de cárie en crianças a partir de 8 meses de idade, numa comunidade do Canadá com grande prevalência de cárie, que atingiu 20\% dos bebês de 18 meses, chegando a envolver $80 \%$ das crianças de 49 meses.

Em 1987, WALTER et al ${ }^{7}$ apresentaram um estudo preliminar da prevalência de cárie nos primeiros 235 bebês atendidos pela Bebê-Clínica da Universidade Estadual de Londrina (UEL). Os resultados demonstraram que $34 \%$ das crianças de $0-24$ meses aprcsentavam cárie. Em crianças de 24-30 meses a prevalência, segundo BÖ NECKER ${ }^{3}$ (1996), sofre um aumento significativo, onde $62,96 \%$ das crianças tinham cárie.

O aspecto que mais chama a atenção na prevalência de cárie em bebês é a existência ou não de uma atenção precoce na comunidade onde vivem, WALTER et al 8 (1996).

GOEPFERD ${ }^{4}$, em 1989, informou que, baseados numa séric de fatos e entre esses a ocorrência de cárie de mamadeira em bebês, a Universidade de Iowa, estabeleceu durante 18 meses, um programa destinado a diagnosticar, interceptar e modificar práticas caseiras que poderiam ser danosas para a saúde bucal da criança. Com base nos resultados obtidos, indicaram que a $1 .^{a}$ visita da criança ao dentista deve ser efetuada por volta dos 6 meses de idade, época em que se consegue maior eficácia na atenção primária e controle de cárie dentária.

No Brasil, os pacientes que recebem a atenção precoce na Bebê-Clínica da UEL apresentam uma redução drástica da prevalência de cárie, cuja prevalência média na faixa etária de 0-48 meses foi de $5,26 \%$, segundo ZOLI et al ${ }^{9}(1995)$.

Porém, esse processo de prevenção e manutenção da saúde bucal da criança (baixo risco), assim como a remoção, o controle ou adequação dos fatores de risco nos pacientes de médio e alto risco somente será conseguido através da conscientização dos pais quanto aos fatores de risco da cáric na ! ${ }^{2}$ infância.

A cárie tem vários fatores que interagem para o scu aparecimento. Um destes fatores, a placa bacteriana, quando visível nas superfícies vestibulares dos incisivos superiores, foi relatada como o melhor sinal de risco de cárie em crianças de pequena idade, segundo ALALUUSUA $E$ MALMIVIRTA ${ }^{2}$ (1994).

Portanto, o presente trabalho se propõe a estudar a presença de placa visível e de cárie dentária em crianças de 18-40 meses de 2 populaçōes distintas, uma con o atendimento precoce e outra sem esse atendimento.

\section{MATERALE METODO}

- AMOSTRA: Foram examinadas 70 crianças de 18 a 40 meses de idade de ambos os sexos que frequientam duas creches da cidade de Londrina, obtendo-se uma amostra aproximada de $90 \%$ de crianças nessa faixa etária, em cada creche.

Das 70 crianças, 35 frequientam a Creche da UEL, uma extensão do programa da Bebè-Clínica no setor público e recebem, portanto, todo o tratamento educativo e preventivo preconizado pelo programa, com exceção do tratamento curativo, realizado na própria Bebê-Clínica.

As outras 35 crianças freqüentam o Centro Integrado de Vivência e Assistência à Criança-Cidade da Criança (Super-Creche), que não possui nenhum tipo de atenção odontológica para as crianças, bem como qualquer educação para os pais. 
- EXAME CLINICO: Para a realização do exame clínico utilizou-se o método visual, e as crianças foram posicionadas de acordo com o Sistema Perna-Perna ou Joelho-Joelho relatado, em 1982, por MATHEWSON et al 6 (1982).

Nas 70 crianças estudadas, observou-se a presença de placa visível na superfície vestibular dos incisivos superiores e a presença de cárie dentária ou não nessas crianças.

- FICHA CLÍNICA: As observações foram, então, transcritas em uma ficha especialmente elaborada, composta de 2 partes: uma para identificação (contendo dados relativos a nome, idade, data de nascimento e sexo) e a outra para anotações clínicas (contendo os ítens presença de placa visível em 2 dentes, presença de placa visível $\mathrm{cm} 4$ dentes, ausência de placa visível e presença de cáric).

- ANÁLISE ESTATÍSTICA: Os dados obtidos foram analisados estatisticamente pelo teste Qui-Quadrado $\left(\mathrm{X}^{2}\right)$ com correção de Yates.

Os resultados foram utilizados em números absolutos testados pelo $\mathrm{X}^{2}$ ao nível de significância de $1 \%$.

\section{RESULTADOS}

Ná TABELA I estão expressos os resultados obtidos quanto ao percentual de crianças com presença de placa visível em 2 ou 4 dentes, ausência de placa visível e presença de cáric dentária na população da Creche da UEL.

TABELA 1-Percentual de crianças com presença ou ausência de placa visível e presença de cárie na Creche da UEL. Londrina, 1996.

\begin{tabular}{ccccc} 
POPLLAÇOAO & $\begin{array}{c}\text { PLACA 2 UENTES } \\
\%\end{array}$ & $\begin{array}{c}\text { PLACA 4 DENTES } \\
\%\end{array}$ & $\begin{array}{c}\text { SEM PLACA } \\
\%\end{array}$ & $\begin{array}{c}\text { COM CÁRIE } \\
\%\end{array}$ \\
\hline CRECHE UEL & 14,28 & 11,42 & 74,28 & 2,85 \\
\hline
\end{tabular}

Na TABELA 2 são apresentados os mesmos dados acima citados, porém, com relação à população da Super Creche.

TABELA 2- Percentual de crianças com presença ou ausência de placa visível e presença de cárie na SuperCreche. Londrina, 1996.

\begin{tabular}{ccccc}
\hline POPULAÇÃO & $\begin{array}{c}\text { PLACA 2 DENTES } \\
\%\end{array}$ & $\begin{array}{c}\text { PLACA 4 DENTES } \\
\%\end{array}$ & $\begin{array}{c}\text { SEM PLACA } \\
\%\end{array}$ & $\begin{array}{c}\text { COM CÁRIE } \\
\%\end{array}$ \\
\hline CRECHE UEL & 14,28 & 11,42 & 74,28 & 2,85
\end{tabular}

Na TABELA 3 estão expressos os dados comparativos quanto à presença e ausência de placa visível e a presença de cárie nas 2 populações.

TABELA 3 - Total e percentual de crianças com presença ou ausência de placa visível e presença de cárie nas 2 creches. Londrina, 1996.

\begin{tabular}{|c|c|c|c|c|c|c|}
\hline \multirow[t]{2}{*}{ POPULAÇAO } & \multicolumn{2}{|c|}{ COM PLACA } & \multicolumn{2}{|c|}{ SEM PLACA } & \multicolumn{2}{|c|}{ COM CÁRIE } \\
\hline & TOTAL & $\%$ & TOTAL & $\%$ & TOTAL & $\%$ \\
\hline CRECHE UEL & 9 & 25,70 & 26 & 74,28 & 1 & 2,85 \\
\hline SUPER CRECHE & 24 & 68,57 & 11 & 31,42 & 9 & 25,71 \\
\hline
\end{tabular}

Através do cálculo do $\mathrm{X}^{2}$ obteve-se o valor 12,95 . Na tabela de $X^{2}$ para o nivel de significância de $1 \%$ e com 2 graus de liberdade, encontra-se o valor 9,21. Como o valor calculado é maior que 9,21 podemos dizer que há diferença significante entre as 2 populações.

\section{DISCUSSAO}

Através do tratamento odontológico precoce, a interposição de medidas de higiene é um dos fatores responsáveis pela baixa prevalência de cárie de 0-48 meses, ZOLI et al ${ }^{9}$ (1995).

No trabalho de ALLALUUSUA e MALMIVIRTA 2 (1994), realizado na Finlândia com 92 crianças de 19 meses, quatro variáveis foram estudadas como indicadores de risco de cárie: o uso da mamadeira, a 
presença de placa visîvel na superfície vestibular dos incisivos superiores e a prevalência de cárie e o nível de Streptococcus mutans salivar nas mães. Desses fatores, a presença de placa visível foi considerada o melhor indicador de risco nessas crianças, isto porque, das crianças que tinham presença de placa visível, 63\% apresentaram lesão de cárie.

Na população estudada, verificou-se que houve uma relação entre a presença de placa visível e a presença de cárie dentária, uma vez que, da população que não recebeu o atendimento precoce, $68,57 \%$ apresentou placa visível e presença de cárie em $25,71 \%$ das crianças. Enquanto que, da população que recebeu este atendimento, $25,70 \%$ apresentou placa visível nos dentes e somente $2,85 \%$ apresentou presença de cárie.

\section{CONCLUSÕES}

Após a análise dos resultados obtidos, pode-se concluir que:

1 - A população que não recebeu o atendimento precoce apresentou um maior percentual de placa visível.

2 - A população que apresentou um maior percentual de placa visível apresentou, também, um maior percentual de presença de cárie.

Desta forma, através do atendimento precoce com ênfase na educação dos pais quanto à realização da higiene dental, eliminando a placa bacteriana, conseguese diminuir a presença de cárie e promover a saúde bucal na 1." infância, comprovando que a educação precoce é a melhor prevenção.

\section{REFERÊNCIAS BIBLIOGRÁFICAS}

1 - AlBERT, R. J.; CANTIN, R. Y.; CROSS, H. G.; CASTALDI, C. R. Nursing caries in the Inuit children of the Keewatin. J Canad dent Ass. v.54, n.10, p.7518, oct. 1988.

2 - ALALUUSUA, S.; MALMIVIRTA, R. Early accumulation - a sign for caries risk in young children. Community Dent Oral Epidemiol. v.22, n.5-I, p.273-344, oct. 1994.

3 - BÖNECHER, M. J. S. Estudo epidemiológico da prevalência, distribuição e grau de afecção de cárie dentária em crianças de 0 a 36 meses de idade do município de Diadema - São Paulo - Brasil. São Paulo. 93 p. Dissertação (mestrado) - Faculdade Odontologia da Universidade de São Paulo, 1996.

4-GOEPFERD, S. J. An infant oral health program: the first 18 months. Oral Health. v.79, n. 1, p.21-5, jan. 1989

5 - GRANER, E. A. Estatística. 2.ed. São Paujo: Meihoramentos, 1996. $184 \mathrm{p}$.

6 - MATHEWSON, R.; PRIMOSCH, R. E.; SANGER, R. G.; ROBERTSON, D. Fundamentals of dentistry for children. Chicago: Quintessence, 1982. $726 \mathrm{p}$.

7 - WALTER, L. R. F.; HOKAMA, N.; IEGA, R.; FERELLE, A.; PELANDA, V. L. G.; FROSSARD, W. T. G.; FRANCO, M. P. S. Plano de Atendimento Odoniológico no primeiro ano de vida. Londrina. Relatório de Pesquisa, Projeto FINEP - Universidade Estadual de Londrina ${ }^{\circ}$ 43.85.0053.00, 1987.

8 - WALTER, L. R. F.; FERELLE, A.; ISSAO, M. Odontologia para o bebê. 1.ed. Artes Médicas, 1996. $246 \mathrm{p}$.

9 - ZOLI, A. F. A.; WALTER, L. R. F.; DEZAN, C. Análise do padrão de higiene, alimentação e uso de flúor em crianças de 0 a 48 meses. In: CONGRESSO UNIVERSITÁRIO BRASILEIRO DE ODONTOLOGIA. São Paulo, 1995. Anais. p.14. 